OPEN ACCESS

Edited by:

Michael Thomas-Poulsen, University of Copenhagen, Denmark

Reviewed by:

Paul Alan Hoskisson, University of Strathclyde, UK Johannes F. Imhoff, GEOMAR Helmholtz Centre for Ocean Research Kiel, Germany Marie Elliot,

McMaster University, Canada

*Correspondence: Matthew F. Traxler mtrax@berkeley.edu

tThese authors have contributed equally to this work.

Specialty section: This article was submitted to Antimicrobials, Resistance and Chemotherapy,

a section of the journal

Frontiers in Microbiology

Received: 15 October 2016 Accepted: 20 December 2016 Published: 17 January 2017

Citation:

Behie SW, Bonet B, Zacharia VM, McClung DJ and Traxler MF (2017)

Molecules to Ecosystems:

Actinomycete Natural Products In situ. Front. Microbiol. 7:2149.

doi: 10.3389/fmicb.2016.02149

\section{Molecules to Ecosystems: Actinomycete Natural Products In situ}

\author{
Scott W. Behiet, Bailey Bonet ${ }^{\dagger}$, Vineetha M. Zacharia, Dylan J. McClung and \\ Matthew F. Traxler*
}

Department of Plant and Microbial Biology, University of California, Berkeley, Berkeley, CA, USA

Actinomycetes, filamentous actinobacteria found in numerous ecosystems around the globe, produce a wide range of clinically useful natural products (NP). In natural environments, actinomycetes live in dynamic communities where environmental cues and ecological interactions likely influence NP biosynthesis. Our current understating of these cues, and the ecological roles of NP, is in its infancy. We postulate that understanding the ecological context in which actinomycete metabolites are made is fundamental to advancing the discovery of novel NP. In this review we explore the ecological relevance of actinomycetes and their secondary metabolites from varying ecosystems, and suggest that investigating the ecology of actinomycete interactions warrants particular attention with respect to metabolite discovery. Furthermore, we focus on the chemical ecology and in situ analysis of actinomycete NP and consider the implications for NP biosynthesis at ecosystem scales.

Keywords: actinomycetes, natural products, in situ, chemical ecology, microbial interactions

\section{INTRODUCTION}

Of the top ten leading causes of death in 1900, three were bacterial infections, and they accounted for greater than one third of total deaths in the US (Jones et al., 2012). Today, bacterial infections are absent from the top ten list due to the discovery and development of antibiotics from fungi and bacteria. In 1943 the first actinomycete-produced therapeutic, streptomycin, was discovered by Albert Schatz, Elizabeth Bugie, and Selman Waksman and was rapidly put into use to treat tuberculosis (Schatz et al., 1944). Actinomycetes are remarkable Gram-positive, filamentous, bacteria responsible for producing an estimated $70 \%$ of the antibiotics used in human therapy (Bérdy, 2005), making them the most robust natural source of antibiotics. Antibiotics and other unique compounds produced by actinomycetes are known as natural products (NP), or secondary or specialized metabolites $(\mathrm{SM})$.

Historically, most discoveries of NP from actinomycetes have involved their growth in rich media, in monoculture, which is strikingly different from their natural environment. During the "golden era" of antibiotics discovery in the 1950s and 1960s, this method worked remarkably well, and lead to a rapid increase in the number of medically relevant NP found from bacteria, including anti-cancer therapeutics, immunosuppressants, and anthelminthics (Bérdy, 2005). From the 1980s and onward the discovery of novel NP from actinomycetes began dropping precipitously as compound re-discovery emerged as a major impediment (Van Middlesworth and Cannell, 1998). The 1990s and 2000s witnessed the large-scale shutdown of most commercial efforts to isolate novel 
compounds from actinomycetes. This situation was, and continues to be, exacerbated by the rise of antibiotic resistance in pathogenic microbes.

Now, in the post-genomic era, with thousands of actinomycete genome sequences available, we have come the realization that actinomycetes possess the genetic capability to produce a multitude of NP never before observed in the laboratory. This realization, coupled with advances in genetic tools, has rekindled interest in exploring actinomycete NP in new and creative ways. Some of these strategies include physiological or genetic manipulation, sampling actinomycetes from new sources, using methods to isolate rare actinomycetes, and coculturing (Bode et al., 2002; Traxler et al., 2013; Yamanaka et al., 2014; Harvey et al., 2015; Pimentel-Elardo et al., 2015). Beyond these, efforts that capitalize on genome mining supported by massive sequencing efforts (Doroghazi et al., 2014; Ju et al., 2015; Goering et al., 2016), high-throughput heterologous expression of NP gene clusters from environmental DNA (Subramani and Aalbersberg, 2013; Milshteyn et al., 2014; Iqbal et al., 2016), NP pathway re-factoring and heterologous expression, in situ cultivation of 'unculturable' bacterial strains [e.g., the iChip, (Ling et al., 2015)], and the MS-guided genomemining (termed peptidogenomics) (Kersten et al., 2011), have been undertaken. Many of these efforts have yielded exciting payoffs in terms of compound discoveries in just the past few years, hinting that a new era of discovery may be at hand.

While developing new ways to discover NP has been, and will certainly continue to be, an important goal, our understanding of the ecological role of these NP is relatively primitive. We suggest that understanding the ecological relevance of these molecules for the microbes that make them is of great importance to inform future strategies for NP discovery. For example, if we can fully understand the environmental cues that stimulate NP production in situ we can exploit these cues in the laboratory to induce normally silent NP gene clusters. Our nascent understanding has lead researchers to propose that NP may play a role in competition for resources, communication and signaling with other organisms, or defense of a symbiotic partner (Davies et al., 2006; Linares et al., 2006; Ryan and Dow, 2008; Cornforth and Foster, 2013; Abrudan et al., 2015). While the initial experiments underpinning these hypotheses are important first steps toward understanding NP ecology, relatively few studies have actually detected the effects of NP in situ.

This review focuses on studies where actinomycete NP biosynthesis has been shown in situ. We briefly review these systems and consider the possible implications of NP activity within their respective ecological contexts, both at a proximate and indirect level. Actinomycete NP from soil or marine sediments have been addressed in recent reviews (Subramani and Aalbersberg, 2012; Traxler and Kolter, 2015), and therefore we do not address them here. The role of actinomycetes in symbiotic relationships has also been recently reviewed, and thus we emphasize studies post-2012 (Seipke et al., 2012). We conclude by considering new tools and experimental paradigms that hold promise for exploring the chemical ecology of actinomycete NP in the future.

\section{USE OF ACTINOMYCETE NATURAL PRODUCTS BY FUNGUS-FARMING ANTS}

One of the most extensively characterized natural systems that harbor actinomycetes is that of the leaf-cutter ants. Actinobacteria associated with fungus-growing leaf-cutter ants produce NP that have been shown to have key roles in shaping this ecosystem (Figure 1) (Currie et al., 1999). Primarily found in the Americas, leaf-cutter ants (including the genera Atta and Acromyrmex) maintain a delicately balanced network that includes their fungal food source, Leucoagaricus gongylophorus, and actinomycetes, which produce antimicrobials to protect the fungal gardens against pathogen invasion (Schultz and Brady, 2008; Hölldobler and Wilson, 2010; Andersen et al., 2015). If the balance of the microbial community is perturbed, fungal pathogens belonging to the Escovopsis genus can invade the fungal garden, resulting in reduced garden biomass and the eventual destruction of entire ant colonies (Currie et al., 2003; Reynolds and Currie, 2004). Ultimately, the NP synthesized by the symbiotic actinobacteria play a critical role in preserving the overall fitness of leaf-cutter ant colonies by protecting L. gongylophorus from pathogen infection.

Actinomycetes predominantly belonging to the Streptomyces and Pseudonocardia genera are also directly associated with the cuticle of leaf-cutter ants. These actinomycetes were studied in assays against invading fungal species and were found to produce a suite of antifungals including antimycins, candicidin, dentigerumycin, and nystatin variants which suppress Escovopsis and other potential pathogens while leaving L. gongylophorus unharmed (Haeder et al., 2009; Seipke et al., 2012; Dângelo et al., 2016). More recently, Sit et al. (2015) discovered, and chemically characterized, new antifungals related to dentigerumycin, called gerumycins, synthesized by Pseudonocardia spp. associated with both Apterostigma dentigerum, and the Trachymyrmex cornetzi ant (Sit et al., 2015). To add another level of complexity to this ecological system, the NP synthesized by leaf-cutter ant actinomycetes may also serve to fend off closely related bacteria that may displace the resident strain (Poulsen et al., 2007). This antagonism between different species of ant-associated Pseudonocardia was pronounced in more distantly related species, suggesting that competition between Pseudonocardia have shaped this association from its evolutionary origin (Poulsen et al., 2007). Consistent with this idea, Van Arnam et al. (2015) recently found that one Pseudonocardia strain produced a novel rebeccamycin analog that inhibited the growth of competing Pseudonocardia (Figure 1). PacBio sequencing of these strains revealed variations in the rebeccamycin BGCs which were located on plasmids, suggesting plasmid-encoded niche defense (Van Arnam et al., 2015). Furthermore, rebeccamycins are of interest to human health since they possess anti-tumor activities and are currently being tested in clinical trials ( $\mathrm{Xu}$ and Her, 2015). 


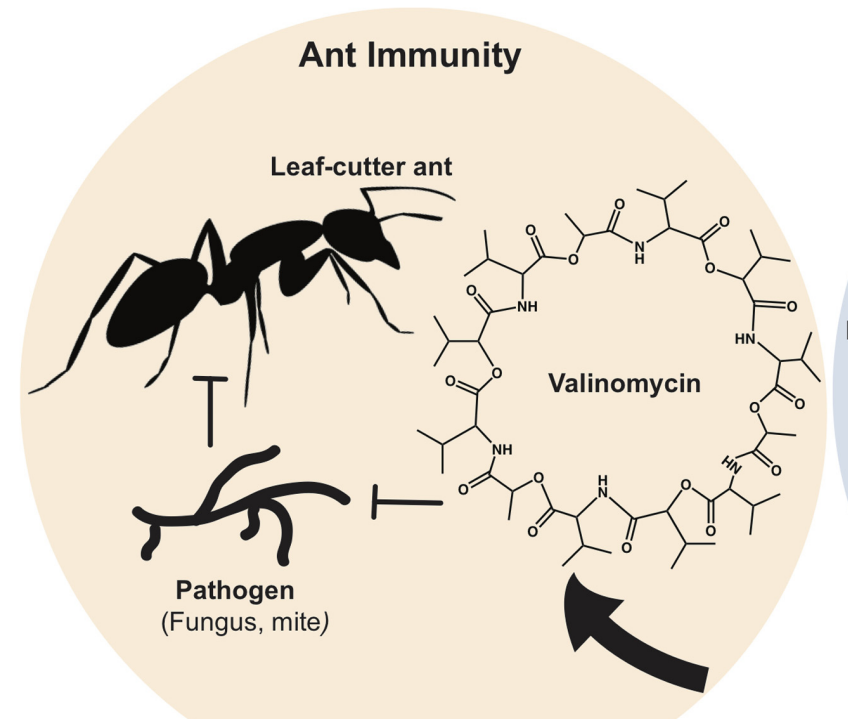

\section{Fungal Pathogen Inhibition}

Actinomycetes

treptomyces spp., Pseudonocardia spp.)
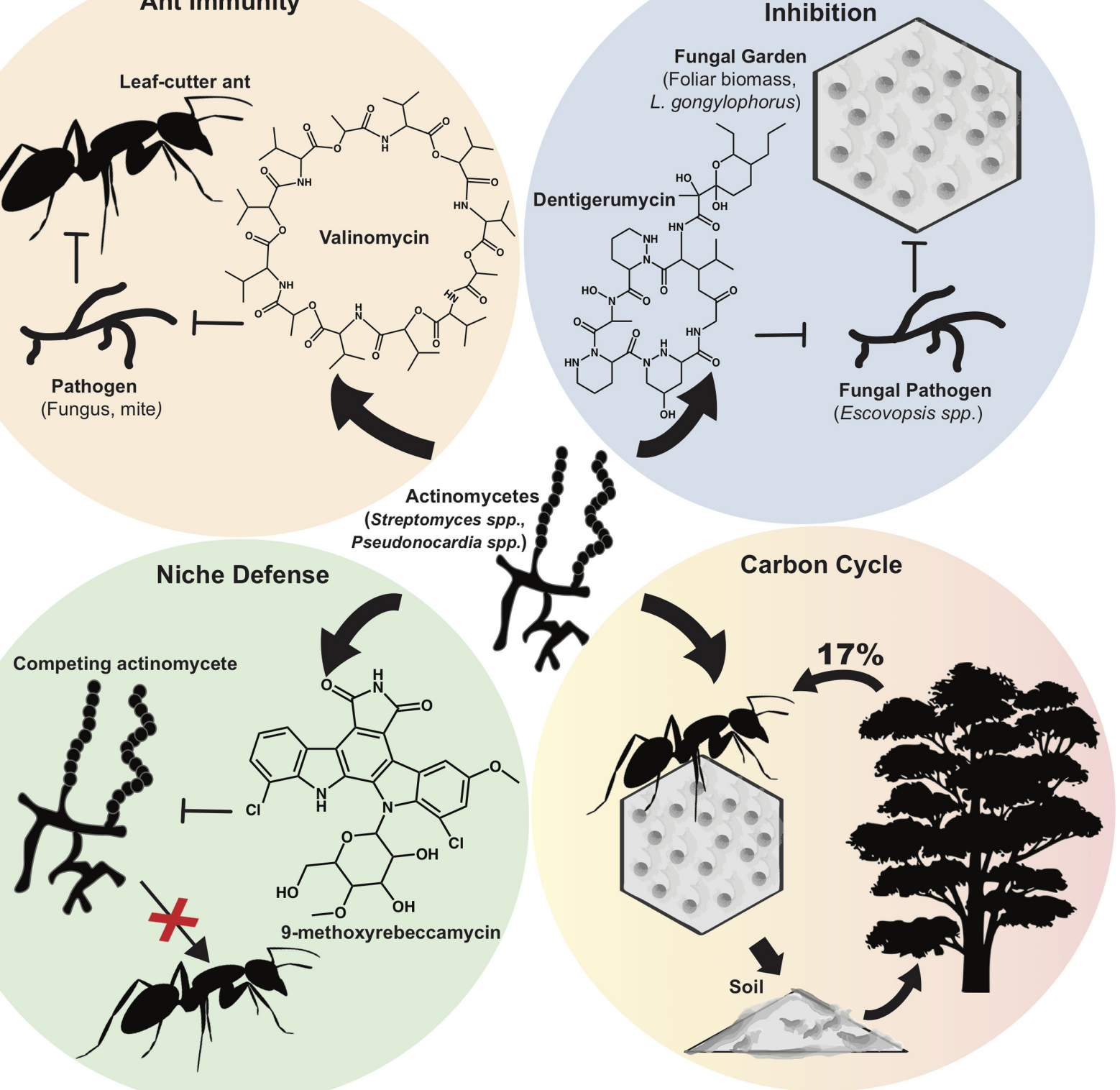

Carbon Cycle

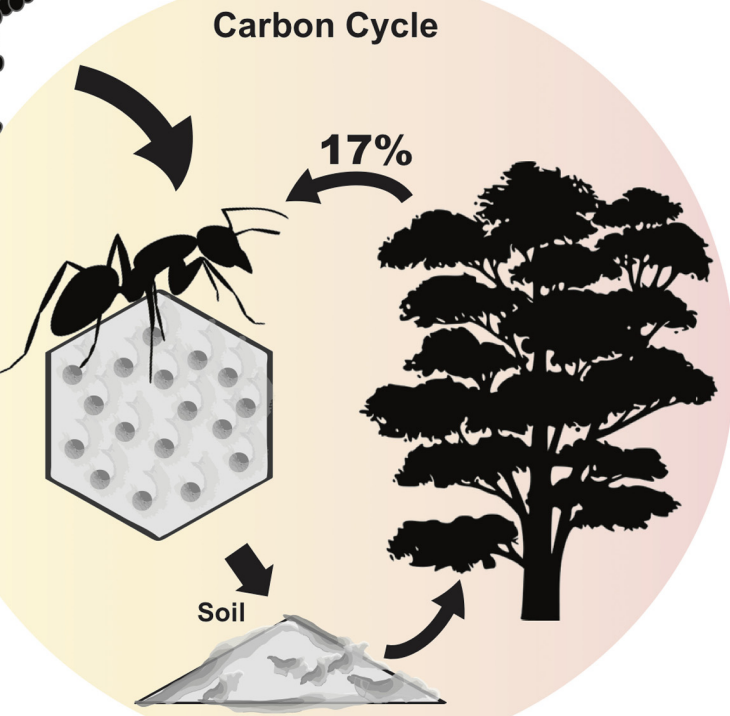

FIGURE 1 | Roles of actinomycete natural products in the leaf-cutter ant ecosystem. Different actinomycete species isolated from attine ant integument (Streptomyces spp., Pseudonocardia spp., etc.) secrete natural products with various functions and roles. (Top left) Streptomyces spp. confer ant immunity by producing valinomycin, antimycins, and actinomycins, which inhibit pathogens and parasites. (Top Right) Actinomycetes produce a range of antifungals including dentigerumycins, candicidin, and nystatin variants, which inhibit fungal pathogens (e.g., Escovopsis spp.) but are not detrimental to the attine ant fungal symbiont, L. gongylophorus. (Bottom Left) Pseudonocardia competing for residency on the ant integument use plasmid-encoded niche defense mechanisms by synthesizing 9-methoxyrebeccamycin. (Bottom Right) Natural products from actinomycetes help preserve the attine ant community, which in turn, affects the larger ecosystem. Leaf-cutter ants forage up to $17 \%$ of the foliar biomass and the L. gongylophorus symbiont helps degrade organic material, which collectively contributes to carbon turnover.

Interestingly, recent evidence suggests that the direct interaction of actinomycetes with their leaf-cutter ant hosts is beneficial for worker ant protection from pathogenic fungi and bacteria (Schoenian et al., 2011; Mattoso et al., 2012; de Souza et al., 2013). With high resolution mass spectrometry (LCESI-HR-MS), and matrix-assisted laser desorption ionization
(MALDI) imaging on the bodies of the ants, Schoenian et al. (2011) identified valinomycins, actinomycins, and antimycins from Streptomyces isolates associated with the integument of Acromyrmex echinatior workers. In their bioassays, Schoenian et al. (2011) demonstrated the inhibitory effects of these NP on insect pathogens such as Metarhizium anisopliae, and Cordyceps 
militaris, and on Escovopsis weberi and Fusarium decemcellulare, which are fungal pathogens of the fungus garden. Strikingly, the MALDI-imaging data clearly showed the localization of valinomycin secreted by Streptomyces on the ant cuticle at varying concentrations. Taken together, these data suggest that the presence of integumental biofilms and their secreted NP work in concert to protect fungal gardens from invading bacteria and fungi, while simultaneously contributing to worker ant immunity by inhibiting the growth of entomopathogens (Figure 1) (Schoenian et al., 2011). To corroborate the importance of actinomycete NP in their protective roles against ant-specific pathogens, cuticle-associated biofilms were removed with antibiotic treatment, thereby exposing the ants to attack by the entomopathogenic fungus $M$. anisopliae, which resulted in increased mortality of Acromyrmex ants (Mattoso et al., 2012). Furthermore, the immunity of Acromyrmex subterraneus ants with and without their symbiotic actinomycetes was evaluated. In their study, de Souza et al. (2013) observed that young worker ants lose their bacterial coating and mature into older, external worker ants. Furthermore, they found that in the absence of their associated bacteria, the young ants had an altered innate immune response, indicating that the actinomycetes confer protection to young internal workers until their immune systems have matured (de Souza et al., 2013). These works collectively stand as a rare concrete example in which the actinomycetes have been removed from the system and their influence ascertained, with the overall result being that their hosts became vulnerable to disease. The authors of these works logically conclude that the most likely reason for this is the activity of the NP made by the actinomycetes in situ. Ultimately this hypothesis might be tested in the future by re-colonizing ants with mutant actinomycete strains lacking the ability to make specific NP. The study of Seipke et al. (2011) takes a step toward conducting this type of experiment as they generated Streptomyces mutant strains unable to synthesize candicidin and antimycin (verified by PCR and LC-MS) and tested its bioactivity toward fungi in vitro (Seipke et al., 2011). The results, however, were inconclusive in terms of mutant effect, therefore it was not tested in situ. This highlights the challenge of executing complex, in situ microbial ecology.

As they are the dominant herbivores in much of the Neotropics (Costa et al., 2008), the foraging activity of leafcutter ants has a large impact in the overall function of their ecosystems (Figures 1 and 2). These ants forage up to $17 \%$ of the foliar biomass and contribute substantially to carbon turnover in their forest habitats (Costa et al., 2008). Their fungal crop, L. gongylophorus, produces lignocellulases capable of breaking down plant polymers (Aylward et al., 2013), which contribute significantly to organic material degradation and reintroduction into the neotropical terrestrial environment. As described above, actinomycete NP likely play a role in protecting the ant's fungal gardens from invasion, and also play a role in protecting the ants themselves from parasites and diseases. While equivocally assessing the direct contribution of these NP is extremely challenging at an ecosystem scale, this body of evidence supports the notion that actinomycete NP are intimately involved in maintaining one of the largest herbivory cycles on earth.
We also note that actinomycetes are associated with nonattine ants such as the Japanese carpenter ant (Camponotus japonicus). The actinomycetes Nocardia camponoti sp. and Promicromonospora alba sp. were recently isolated from the heads of these ants, and their genomes were sequenced (Guo et al., 2016; Liu et al., 2016). While the NP repertoire of these strains has not yet been explored, further study of these newly reported interactions might lead to the discovery of novel bioactive compounds that play a role in shaping the Japanese carpenter ant's ecosystem.

\section{OFFSPRING PROTECTION VIA ACTINOMYCETE NATURAL PRODUCTS BY BEEWOLF WASPS}

The beewolf digger wasps (Philanthus spp., Hymenoptera, Crabronidae) live in a symbiosis with the streptomycete Candidatus Streptomyces philanthi, which is housed within the antennal glands of the female beewolves (Kaltenpoth et al., 2005). Female wasps deposit this bacterial symbiont onto the inner walls of the protective underground burrows where they lay their eggs. These streptomycetes are incorporated into the silk as the larvae begin spinning their cocoons (Kaltenpoth et al., 2006). The cocoons remain immobile in the humid burrows, and are thus easy targets for fungal and bacterial pathogens that live in the soil or are introduced by the honeybees brought into the burrow as a food source for the larvae (Kaltenpoth et al., 2005). However, the streptomycete symbionts protect the cocoons by secreting nine antimicrobial or antifungal compounds onto the outer surface of the cocoon (Kroiss et al., 2010; Seipke et al., 2012; Koehler et al., 2013).

Kroiss et al. (2010) were able to detect three of these compounds, the antibiotics piericidin $A_{1}$, piericidin $B_{1}$, and streptochlorin in situ. They further elucidated that there was a uniform distribution of all three compounds on the outer surface of the cocoon as compared to the inner surface (Kroiss et al., 2010). This distribution of antimicrobials suggests that the metabolites protect the cocoon from invading pathogens on the outside, but are at lower concentrations inside to prevent disruption of larval development. Four of the nine antimicrobials were shown to be inhibitory to the growth of 10 soil fungi and bacteria that would likely pose a threat of infection to the cocoons such as Aspergillus and Metarhizium (Strohm and Linsenmair, 2001; Kroiss et al., 2010). In situ analysis with MALDI-TOF/MS in conjunction with fluorescence in situ hybridization (FISH), showed that the insect associated streptomycetes co-localize with piericidin $A_{1}$ and $B_{1}$ (Kaltenpoth et al., 2016). This data illustrates the role of Streptomyces produced antimicrobials in situ that protect the beewolf cocoon from potential microbial infections, ensuring offspring survival.

At an ecosystem level, it is challenging to imagine what the overall effect of these actinomycete-produced compounds might be. However, this system is notable because it is one of the few examples in which NP from actinomycetes have been visualized in situ. To the extent that this system may be manipulated at 


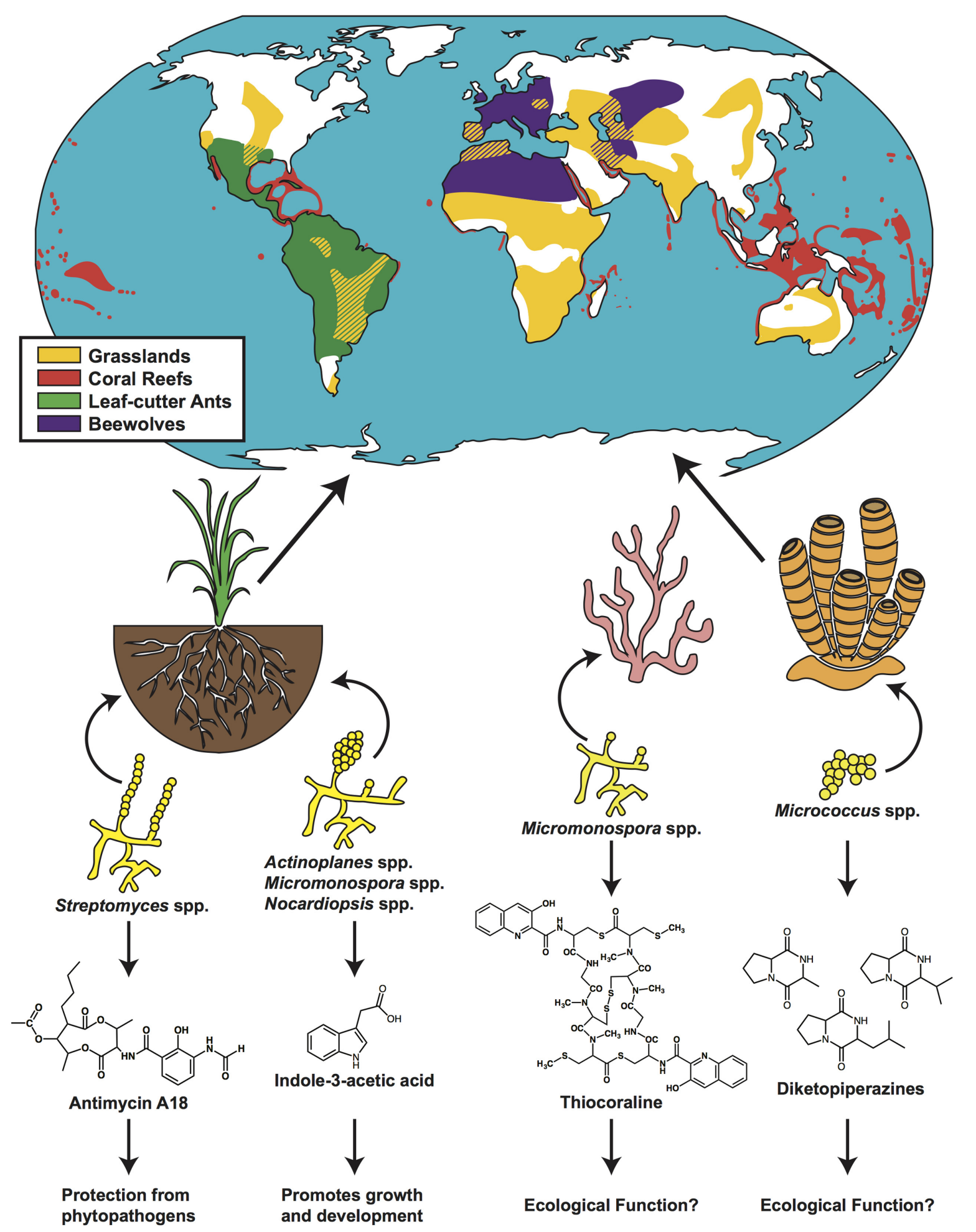

FIGURE 2 | Actinomycete-produced natural products aid in ecosystem function across the globe. Distributions of grasslands (yellow), coral reefs (red), leaf-cutter ants (green), and beewolves (purple) are denoted on a map of the globe. Representative actinomycetes and the natural products that they produce in rhizosphere, coral and sponge communities are shown. Distribution maps adapted from: www.thinglink.com/scene/655045986153922561 (grasslands); www.antweb.org/antblog/2011/03/geographic-range- of-leaf-cutter-ants-don-indianapolis-in-usa.html (leaf-cutter ants); www.grida.no/graphicslib/ detail/distribution-of-coldwater-and-tropical-coral-reefs_1153 (coral reefs); Herzner and Strohm, 2008 (beewolf). 
the genetic and chemical level, it may represent one of the best opportunities for assessing the direct impact, and therefore the bona fide role, of a NP made by an actinomycete in a natural setting.

\section{ACTINOMYCETE SPECIALIZED METABOLISM IN THE RHIZOSPHERE}

Actinomycetes that inhabit the rhizosphere have been shown to secrete a wide range of NP that can contribute to defense against pathogenic bacteria and fungi, and aid in plant nutrient scavenging (El-Tarabily et al., 2009; Solans et al., 2011; Rungin et al., 2012; Harikrishnan et al., 2014). Rhizosphere soils contain relatively high levels of actinobacteria (Hirsch and Mauchline, 2012), and the relationship between soil actinomycetes and plant roots can have dramatic effects on plant health.

Root-colonizing Streptomyces have been found to produce a number of antifungal and antimicrobial compounds in situ such as staurosporine, 3-acetonylidene-7-prenylindolin-2one, diastaphenazine, and antimycin A18 (Yan et al., 2010; Li et al., 2014, 2015; Zhang et al., 2014). These in situ analyses offer a critical lens for beginning to understand bioactive compound production in the natural context of the rhizosphere. Studies examining the large-scale effect of rhizosphere actinomycetes have been done with respect to plant health and disease resistance. For example, when cucumber plants (Cucumis sativus) were inoculated with one or a combination of three endophytic actinomycetes, Actinoplanes campanulatus, Micromonospora chalcea, or Streptomyces spiralis, the overall effects of Pythium aphanidermatum, a soil-borne, fungal phytopathogen, were mitigated. Specifically, host plants showed significantly less root and crown rot, and were healthier overall (El-Tarabily et al., 2009). A number of other studies have shown similar results, in various plant systems, where root-inoculated actinomycetes were able to protect the plant from harmful pathogen invasion (Xue et al., 2013; Nabti et al., 2014; Solans et al., 2016). In a notable example, Streptomyces lividans was shown to produce prodiginines on the roots of Arabidopsis thaliana, which antagonized the particularly damaging fungal pathogen Verticillium dahlia (Meschke et al., 2012). The ability of rhizosphere-inhabiting actinomycetes to produce a large range of metabolites antagonistic to phytopathogens, and subsequently provide protection, point to an important role for soil actinomycetes in ensuring plant health and primary production (Figure 2).

Soil actinomycetes are also known to enhance plant health by stimulating plant growth and development through the production of phytohormones (Solans et al., 2011; Harikrishnan et al., 2014). Endophytic actinomycetes such as Nocardiopsis, Actinoplanes spp., and Micromonospora have been found to produce a number of important phytohormones such as indole-3-acetic acid (IAA) (Figure 2) and indole-3pyruvic acid (IPYA), compounds required for fundamental plant functions including coordinated cell growth, and gene regulation (Subramaniam et al., 2016). This suite of compounds has been specifically shown to promote growth and development in wheat, lettuce, rye, and tomato (Merzaeva and Shirokikh, 2010; Bonaldi et al., 2015; Abbamondi et al., 2016; Toumatia et al., 2016). Directly delineating microbially produced phytohormones, as opposed to phytohormones made by the host, is technically challenging. However, the in vitro production of these compounds by root colonizing, or rhizosphere competent, actinomycetes suggests a potential means by which the soil microbiome is able to impact plant health (Figure 2).

Soil Streptomyces are also capable of enhancing the overall nutrient acquisition efficiency of plants by promoting the growth of critical symbiotic nitrogen fixers such as Rhizobia, and by aiding in root nutrient scavenging. Leguminous plants enter into a symbiosis with bacteria of the Rhizobiales clade in which the bacterium stimulates the plant to produce a root nodule that house the bacteria. In turn the bacteria fix atmospheric nitrogen, making it available to the plant. When chickpea plants were inoculated with Streptomyces, the result was increased nodulation as well as an increase in nodule size suggesting an overall stimulating effect on the nitrogen-fixing capability of the plant (Gopalakrishnan et al., 2015). This is especially notable given that fixed nitrogen is a limiting resource for plants in all systems. The production of siderophores by actinomycetes within the rhizosphere, or directly on the root, can specifically aid the plant in scavenging iron from surrounding soils (Rungin et al., 2012). Through the production of their own siderophores, plants are able to scavenge the soil for soluble iron ( $\mathrm{Ma}, 2005)$. However, plants are also able to uptake iron-bound, actinomyceteproduced, siderophores, increasing their overall iron uptake efficiency.

The example studies highlighted above point to a ubiquitous association between actinomycetes and plant roots in the rhizosphere. By in large, this association is beneficial for plants as they may receive multiple chemical inputs from actinobacteria, including siderophores, phytohormones, antibiotics, and antifungals that inhibit potential pathogens (Solans et al., 2011; Rungin et al., 2012; Harikrishnan et al., 2014; Li et al., 2014; Zhang et al., 2014). Most studies have examined actinomycete/plant relationships in the context of food crops, some of which are grasses such as wheat, sorghum, rye, maize, and rice (Bressan, 2003; Merzaeva and Shirokikh, 2010; Harikrishnan et al., 2014; Toumatia et al., 2016). Beyond this, metagenomic and culture-based studies of rhizosphere soil from grasslands have revealed a wide array of plant-associated actinomycetes (Lugo et al., 2007; Delmont et al., 2012). Based on this collective evidence, we suggest that chemical interactions between actinomycetes and plants (especially non-woody plants) are likely to influence plant health at an ecosystem scale, especially in grasslands (Figure 2). Though the exact in situ role of each actinomycete produced NP is not fully understood, it is clear that the presence of actinomycetes alter the plant's susceptibility to pathogens, nutrient uptake, and growth. Of course, other microbes also likely to play a major role in these complex interaction webs, but the large 
number of NP produced by actinomycetes may make their role unique.

\section{ACTINOMYCETE NATURAL PRODUCTS IN MARINE ORGANISMS}

The ocean covers $70 \%$ of the earth's surface and is responsible for $50 \%$ of the earth's daily primary productivity, which amounts to an estimated 140 million tons of carbon production per day (Field et al., 1998). Actinomycetes have been found in many marine habitats including marine sediments, estuaries, fish, mollusks, mangroves, and seaweeds, and marine actinomycetes have long been a productive source of prospecting for novel NP. Isolating actinomycetes from marine sediments has proven to be a successful strategy for discovery of potent bioactive molecules (Fenical et al., 2009) and coupling this with sequencing efforts has shown that there is great potential still to be discovered (Udwary et al., 2007; Ziemert et al., 2014). For now we will focus on coral reefs and marine sponges as these are the best studied marine actinomycete environments. Studies have measured the diversity and abundance of actinobacterial symbionts, finding that they are ubiquitously and stably associated within these systems (Abdelmohsen et al., 2014; Braña et al., 2015; Mahmoud and Kalendar, 2016). Subsequently, actinomycetes have been isolated from various sponges and corals to investigate their antimicrobial activities and potential to produce novel bioactive compounds (Schneemann et al., 2010; Cheng et al., 2015; Kuang et al., 2015; Pham et al., 2015; Mahmoud and Kalendar, 2016). The isolates have proved to be a rich source of NP with antifungal, antimicrobial, anti-cancer, and anti-HIV compounds (Abdelmohsen et al., 2014).

The majority of these studies involved isolating the actinomycetes and culturing them in the laboratory setting. Comprehensive laboratory analyses done on sponge associated actinomycetes has found that a number of different species are culturable from marine sponges, and that they are capable of producing bioactive secondary metabolites (Schneemann et al., 2010; Xi et al., 2012). With respect to the sponge Halichondria panicea, for example, five actinomycete genera were isolated and the bacterial extracts were found to contain secondary metabolites with bioactivities (Schneemann et al., 2010). However, ecological analysis of marine environments remains challenging, and there are few studies that have reported in situ data. Recently, however, Yarnold et al. (2012) used MALDI-MS imaging to map the spatial distribution of brominated pyrrole-2aminoimidazole alkaloids, which have cytotoxic and anti-fouling properties, on cross sections of the marine sponge Stylissa flabellata. These compounds were found in discrete locations within the sponges and were present in high amounts near sites most susceptible to predation and biofouling. There is yet no clear delineation between the suite of metabolites produced by the sponge, and those produced by associated microorganisms, but gradients and pockets of metabolite production suggest that these are likely to be microbially produced. In one specific example, three diketopiperazines, one of which has antibiotic properties, that were isolated and characterized from the sponge
Tedania ignis, were later found to be produced by associated Micrococcus (Figure 2) (Stierle et al., 1988).

Due to the overall paucity of information about specific microbially produced metabolites on marine sponges, there is little information on the roles they may play for their sponge hosts. Recently, however, the genomes of three marine sponge associated actinomycetes (Micromonospora sp. RV43, Rubrobacter sp. RV113, and Nocardiopsis sp. RV163) were sequenced, and subsequently mined for the presence of secondary metabolite producing gene clusters (Horn et al., 2015). All three species under investigation contained gene clusters required to produce NP of known antibiotic and antifungal activity. To study how bacterial symbionts affect the ecology of the sponge, Mehbub et al. (2016) performed controlled aquarium experiments designed to test the effects of increased levels of a sponge-associated actinomycete, Streptomyces ACT-52A, on the sponge's microbial community, metabolite profile, and bioactivity. When Streptomyces ACT-52A was exogenously added to the water in the aquarium, they observed shifts in the microbial community, accompanied by a change in metabolite profile composition and the bioactivity of sponge extracts. Though it is still not clear if the changes in metabolite production were of microbial or sponge origin, it is clear that interactions between the sponge and its associated bacteria can impact NP biosynthesis and microbial diversity. We can envision this as a system where the effect of mutant actinomycetes, deficient in the production of a specific NP, may be tested. A possible next step would be to investigate how the health and function of the sponge, and its associated microbiome, may impact the marine ecosystem as a whole.

Coral reefs themselves have also been of interest with respect to bioprospecting as they house an immense diversity of secondary metabolites (Leal et al., 2013). A large number of these metabolites, however, are produced by symbiotic bacteria living in the corals (Leal et al., 2013). In one instance, thiocoraline, a thiodepsipeptide, was isolated from a coral associated marine actinomycete, Micromonospora marina (Romero et al., 1997). Though thiocoraline was shown to have anti-tumor and antibiotic activity in vitro, no in situ experiments have been done, thus the ecological impacts of this metabolite on the corals remains unexplored (Figure 2). These and other bacterial symbionts potentially have a number of functions with regard to reef health, including protection from invading pathogens. However, the culturing of the majority of marine bacteria remains a major impediment, and thus the analysis of the majority of reef associated actinomycetes remains elusive. Beyond this, large amounts of reef biomass are required for the isolation of coral-associated metabolites, and while the aquaculturing of reefs represents a potentially viable option to produce reef associated metabolites (Leal et al., 2013), the complexity of marine environments is difficult to replicate, and thus the chemical ecology, and symbiotic microbiome, may be drastically different in laboratory experiments (Hay, 1996).

Collectively reefs occupy $<0.2 \%$ of the world's oceans (Figure 2), yet are estimated to be one of the most biodiverse ecosystems on the planet (Knowlton et al., 2010), that includes a panoply of coral and sponge species. Taken together, the studies 
described above point to a long lasting symbioses between corals, sponges, and actinomycetes. As for the other systems addressed in this review, assessing the contribution of actinomycete NP to the overall health and stability of reef ecosystems is challenging. However, any advantage conferred by actinomycete symbiosis is likely to have ecosystem-wide implications. Further studies aimed at understanding the role of these compounds in simplified, controlled aquarium settings may provide a window into the chemical underpinnings of these ecosystems.

\section{CONCLUDING REMARKS}

Accurately assessing the role of a given bacterial species in its natural environment is a daunting task. However, as we transition to the 'age of the microbiome', questions about microbial community function, and community impact on their respective ecosystems, will become increasingly important. Actinomycetes are interesting to consider in this regard since the role played by their extensive NP repertoires has long been the source of speculation. Beyond this, at a practical level, understanding the roles and ecological drivers that stimulate production of these compounds may open new avenues to NP discovery. Only by conducting these kinds of studies, will we begin to understand how these molecules function in natural settings, and what advantages might be gained for the organisms that make these compounds. We suggest that knowledge about the ecological and chemical contexts in which these molecules are used by the producing organisms may provide insights into how we can minimize the development of pathogen resistance and extend the working life of antibiotics in the clinic.

What does it take to effectively evaluate the impact of a NP in situ? The framework for considering this question could be adapted from the fundamental principles of Koch's postulates. Namely, the NP should be detectable in situ, removing the producing organism from the system should eliminate the NP and result in a measureable effect on the system, and replacing the producing organism should lead to detection of the compound in situ and reverse the effect of removing it. Undoubtedly, the most rigorous approach would be to replace the producing organism with a mutant defective in its ability to produce the NP in question, followed by verifying the absence of the NP and assessment of the effect on the system overall. These stringent criteria are obviously challenging to implement in practice, especially in natural settings.

Determining the ecological drivers of NP biosynthesis in situ may ultimately prove even more challenging than assessing the impact of these compounds. However, we suggest that understanding the effect that a given NP has on the surrounding microbial community may provide valuable context

\section{REFERENCES}

Abbamondi, G. R., Tommonaro, G., Weyens, N., Thijs, S., Sillen, W., Gkorezis, P., et al. (2016). Plant growth-promoting effects of rhizospheric and endophytic bacteria associated with different tomato cultivars and new tomato hybrids. Chem. Biol. Technol. Agric. 3:1. doi: 10.1186/s40538-015-0051-3 for considering what cues may be connected to its production. Another starting point will be to understand cues that drive actinomycete specialized metabolism in simple, binary interactions. Surprisingly, while it has been shown many times that binary interspecies interactions can lead to activation of NP biosynthesis (Ueda et al., 2000; Yamanaka et al., 2005; Onaka et al., 2011; Vetsigian et al., 2011; Traxler et al., 2013; Kinkel et al., 2014; Abrudan et al., 2015), a molecular/physiological understanding of this phenomenon remains largely elusive. Only in one case, described by Yamanaka et al. (2005), was a molecule identified as triggering antibiotic production in another nearby strain. In that instance, the stimulatory molecule revealed to be the common siderophore desferrioxamine E. Accordingly, understanding the chemical and mechanistic nature of these interactions is an active area of research being undertaken in multiple labs. Beyond binary interactions, simplified synthetic communities that can be experimentally manipulated will also offer a tractable starting point for assessing connections between cues, NP, and ecosystem effects.

However, difficult it may be to carry out studies on complex natural systems that include microbial communities, the development of new tools provides a reason to be optimistic about future efforts aimed at understanding the ecology of NP. Specifically, advances in mass spectrometry imaging and direct chemical sampling of microhabitats via technologies like NanoDESI MS are making detection of these fascinating molecules in situ a much more tractable prospect. One predictable outcome of removing a molecule with antibiotic or antifungal activity from a microbial community might be a shift in the overall community composition. Fortunately, the best method for assessing these changes, e.g., metagenomic sequencing, has also become radically more accessible. Moreover, as the study of microbiomes advances with the development of model microbial communities and more portable technologies to enable measurement of key microbiome parameters in the field (Alivisatos et al., 2015; Blaser et al., 2016) the questions posed here will become more tractable.

\section{AUTHOR CONTRIBUTIONS}

All authors listed, have made substantial, direct and intellectual contribution to the work, and approved it for publication. SB and $\mathrm{BB}$ are the primary authors of this manuscript.

\section{FUNDING}

Costs related to this article were covered by a Searle Scholar Award to MT.

Abdelmohsen, U. R., Bayer, K., and Hentschel, U. (2014). Diversity, abundance and natural products of marine sponge-associated actinomycetes. Nat. Prod. Rep. 31, 381-399. doi: 10.1039/C3NP70111E

Abrudan, M. I., Smakman, F., Grimbergen, A. J., Westhoff, S., Miller, E. L., van Wezel, G. P., et al. (2015). Socially mediated induction and suppression of antibiosis during bacterial coexistence. Proc. 
Natl. Acad. Sci. U.S.A. 112, 11054-11059. doi: 10.1073/pnas.150407 6112

Alivisatos, A. P., Blaser, M. J., Brodie, E. L., Chun, M., Dangl, J. L., Donohue, T. J., et al. (2015). A unified initiative to harness Earth's microbiomes. Science 350, 507-508. doi: 10.1126/science.aac 8480

Andersen, S. B., Yek, S. H., Nash, D. R., and Boomsma, J. J. (2015). Interaction specificity between leaf-cutting ants and vertically transmitted Pseudonocardia bacteria. BMC Evol. Biol. 15:27. doi: 10.1186/s12862-015-0308-2

Aylward, F. O., Burnum-Johnson, K. E., Tringe, S. G., Teiling, C., Tremmel, D. M., Moeller, J. A., et al. (2013). Leucoagaricus gongylophorus produces diverse enzymes for the degradation of recalcitrant plant polymers in leaf-cutter ant fungus gardens. Appl. Environ. Microbiol. 79, 3770-3778. doi: 10.1128/AEM. 03833- 12

Bérdy, J. (2005). Bioactive microbial metabolites. J. Antibiot. (Tokyo) 58, 1-26. doi: 10.1038/ja.2005.1

Blaser, M. J., Cardon, Z. G., Cho, M. K., Dangl, J. L., Donohue, T. J., Green, J. L., et al. (2016). Toward a predictive understanding of earth's microbiomes to address 21 st century challenges. mBio 7:e714-16. doi: 10.1128/mBio.00714- 16

Bode, H. B., Bethe, B., Höfs, R., and Zeeck, A. (2002). Big effects from small changes: possible ways to explore nature's chemical diversity. ChemBioChem 3 , 619-627. doi: 10.1002/1439-7633(20020703)3:7<619::AID-CBIC619>3.0.CO; 2-9

Bonaldi, M., Chen, X., Kunova, A., Pizzatti, C., Saracchi, M., and Cortesi, P. (2015). Colonization of lettuce rhizosphere and roots by tagged Streptomyces. Front. Microbiol. 6:25. doi: 10.3389/fmicb.2015.00025

Braña, A. F., Braña, A. F., Fiedler, H.-P., Nava, H., González, V., SarmientoVizcaíno, A., et al. (2015). Two Streptomyces species producing antibiotic, antitumor, and anti-inflammatory compounds are widespread among intertidal macroalgae and deep-sea coral reef invertebrates from the central Cantabrian Sea. Microb. Ecol. 69, 512-524. doi: 10.1007/s00248-014-0508-0

Bressan, W. (2003). Biological control of maize seed pathogenic fungi by use of actinomycetes. BioControl 48, 233-240. doi: 10.1023/A:1022673226324

Cheng, C., MacIntyre, L., Abdelmohsen, U. R., Horn, H., Polymenakou, P. N., Edrada-Ebel, R., et al. (2015). Biodiversity, anti-trypanosomal activity screening, and metabolomic profiling of actinomycetes isolated from mediterranean sponges. PLoS ONE 10:e0138528. doi: 10.1371/journal.pone. 0138528

Cornforth, D. M., and Foster, K. R. (2013). Competition sensing: the social side of bacterial stress responses. Nat. Rev. Microbiol. 11, 285-293. doi: 10.1038/ nrmicro2977

Costa, A. N., Vasconcelos, H. L., Vieira-Neto, E. H. M., and Bruna, E. M. (2008). Do herbivores exert top-down effects in Neotropical savannas? Estimates of biomass consumption by leaf-cutter ants. J. Veg. Sci. 19, 849-854. doi: 10.3170/ 2008-8-18461

Currie, C. R., Scott, J. A., Summerbell, R. C., and Malloch, D. (1999). Fungusgrowing ants use antibiotic-producing bacteria to control garden parasites. Nature 398, 701-704. doi: 10.1038/19519

Currie, C. R., Wong, B., Stuart, A. E., Schultz, T. R., Rehner, S. A., Mueller, U. G., et al. (2003). Ancient tripartite coevolution in the attine ant-microbe symbiosis. Science 299, 386-388. doi: 10.1126/science.1078155

Dângelo, R. A. C., de Souza, D. J., Mendes, T. D., Couceiro, J., da, C., and Lucia, T. M. C. D. (2016). Actinomycetes inhibit filamentous fungi from the cuticle of Acromyrmex leafcutter ants. J. Basic Microbiol. 56, 229-237. doi: 10.1002/jobm. 201500593

Davies, J., Spiegelman, G. B., and Yim, G. (2006). The world of subinhibitory antibiotic concentrations. Curr. Opin. Microbiol. 9, 445-453. doi: 10.1016/j.mib. 2006.08.006

de Souza, D. J., Lenoir, A., Kasuya, M. C. M., Ribeiro, M. M. R., Devers, S., Couceiro, J., et al. (2013). Ectosymbionts and immunity in the leaf-cutting ant Acromyrmex subterraneus subterraneus. Brain. Behav. Immun. 28, 182-187. doi: 10.1016/j.bbi.2012.11.014

Delmont, T. O., Prestat, E., Keegan, K. P., Faubladier, M., Robe, P., Clark, I. M., et al. (2012). Structure, fluctuation and magnitude of a natural grassland soil metagenome. ISME J. 6, 1677-1687. doi: 10.1038/ismej.2011.197

Doroghazi, J. R., Albright, J. C., Goering, A. W., Ju, K.-S., Haines, R. R., Tchalukov, K. A., et al. (2014). A roadmap for natural product discovery based on largescale genomics and metabolomics. Nat. Chem. Biol. 10, 963-968. doi: 10.1038/ nchembio. 1659
El-Tarabily, K. A., Nassar, A. H., Hardy, G. E. S. J., and Sivasithamparam, K. (2009). Plant growth promotion and biological control of Pythium aphanidermatum, a pathogen of cucumber, by endophytic actinomycetes. J. Appl. Microbiol. 106, 13-26. doi: 10.1111/j.1365-2672.2008.03926.x

Fenical, W., Jensen, P. R., Palladino, M. A., Lam, K. S., Lloyd, G. K., and Potts, B. C. (2009). Discovery and development of the anticancer agent salinosporamide A (NPI-0052). Bioorg. Med. Chem. 17, 2175-2180. doi: 10.1016/j.bmc.2008. 10.075

Field, C. B., Behrenfeld, M. J., Randerson, J. T., and Falkowski, P. (1998). Primary production of the biosphere: integrating terrestrial and oceanic components. Science 281, 237-240. doi: 10.1126/science.281.5374.237

Goering, A. W., McClure, R. A., Doroghazi, J. R., Albright, J. C., Haverland, N. A., Zhang, Y., et al. (2016). Metabologenomics: correlation of microbial gene clusters with metabolites drives discovery of a nonribosomal peptide with an unusual amino acid monomer. ACS Cent. Sci. 2, 99-108. doi: 10.1021/ acscentsci.5b00331

Gopalakrishnan, S., Srinivas, V., Alekhya, G., Prakash, B., Kudapa, H., Rathore, A., et al. (2015). The extent of grain yield and plant growth enhancement by plant growth-promoting broad-spectrum Streptomyces sp. in chickpea. SpringerPlus 4:31. doi: 10.1186/s40064-015-0811-3

Guo, L., Liu, C., Zhao, J., Li, C., Guo, S., Fan, J., et al. (2016). Promicromonospora alba sp. nov., an actinomycete isolated from the cuticle of Camponotus japonicas Mayr. Int. J. Syst. Evol. Microbiol. 66, 1340-1345. doi: 10.1099/ijsem.0.000885

Haeder, S., Wirth, R., Herz, H., and Spiteller, D. (2009). Candicidin-producing Streptomyces support leaf-cutting ants to protect their fungus garden against the pathogenic fungus Escovopsis. Proc. Natl. Acad. Sci. U.S.A. 106, 4742-4746. doi: $10.1073 /$ pnas.0812082106

Harikrishnan, H., Shanmugaiah, V., and Balasubramanian, N. (2014). Optimization for production on Indole acetic acid (IAA) by plant growth promoting Streptomyces sp VSMGT1014 isolated from rice rhizosphere. Int. J. Curr. Microbiol. Appl. Sci. 3, 158-171.

Harvey, A. L., Edrada-Ebel, R., and Quinn, R. J. (2015). The re-emergence of natural products for drug discovery in the genomics era. Nat. Rev. Drug Discov. 14, 111-129. doi: 10.1038/nrd4510

Hay, M. E. (1996). Marine chemical ecology: What's known and what's next? J. Exp. Mar. Biol. Ecol. 200, 103-134. doi: 10.1016/S0022-0981(96)02659-7

Herzner, G., and Strohm, E. (2008). Food wrapping by females of the European Beewolf, Philanthus triangulum, retards water loss of larval provisions. Physiol. Entomol. 33, 101-109. doi: 10.1111/j.1365-3032.2007.00603.x

Hirsch, P. R., and Mauchline, T. H. (2012). Who's who in the plant root microbiome? Nat. Biotechnol. 30, 961-962. doi: 10.1038/nbt.2387

Hölldobler, B., and Wilson, E. O. (2010). The Leafcutter Ants: Civilization by Instinct. Original Edition. New York, NY: W. W. Norton \& Company.

Horn, H., Hentschel, U., and Abdelmohsen, U. R. (2015). Mining genomes of three marine sponge-associated actinobacterial isolates for secondary metabolism. Genome Announc. 3:e1106-15. doi: 10.1128/genomeA.01106-15

Iqbal, H. A., Low-Beinart, L., Obiajulu, J. U., and Brady, S. F. (2016). Natural product discovery through improved functional metagenomics in Streptomyces. J. Am. Chem. Soc. 138, 9341-9344. doi: 10.1021/jacs.6b02921

Jones, D. S., Podolsky, S. H., and Greene, J. A. (2012). The burden of disease and the changing task of medicine. N. Engl. J. Med. 366, 2333-2338. doi: 10.1056/ NEJMp1113569

Ju, K.-S., Gao, J., Doroghazi, J. R., Wang, K.-K. A., Thibodeaux, C. J., Li, S., et al. (2015). Discovery of phosphonic acid natural products by mining the genomes of 10,000 actinomycetes. Proc. Natl. Acad. Sci. U.S.A. 112, 12175-12180. doi: 10.1073/pnas.1500873112

Kaltenpoth, M., Goettler, W., Dale, C., Stubblefield, J. W., Herzner, G., Roeser-Mueller, K., et al. (2006). "Candidatus Streptomyces philanthi”, an endosymbiotic streptomycete in the antennae of Philanthus digger wasps. Int. J. Syst. Evol. Microbiol. 56, 1403-1411. doi: 10.1099/ijs.0.64117-0

Kaltenpoth, M., Göttler, W., Herzner, G., and Strohm, E. (2005). Symbiotic bacteria protect wasp larvae from fungal infestation. Curr. Biol. 15, 475-479. doi: 10. 1016/j.cub.2004.12.084

Kaltenpoth, M., Strupat, K., and Svatoš, A. (2016). Linking metabolite production to taxonomic identity in environmental samples by (MA)LDI-FISH. ISME J. 10, 527-531. doi: 10.1038/ismej.2015.122

Kersten, R. D., Yang, Y.-L., Xu, Y., Cimermancic, P., Nam, S.-J., Fenical, W., et al. (2011). A mass spectrometry-guided genome mining approach for natural 
product peptidogenomics. Nat. Chem. Biol. 7, 794-802. doi: 10.1038/nchembio. 684

Kinkel, L. L., Schlatter, D. C., Xiao, K., and Baines, A. D. (2014). Sympatric inhibition and niche differentiation suggest alternative coevolutionary trajectories among Streptomycetes. ISME J. 8, 249-256. doi: 10.1038/ismej.2013.175

Knowlton, N., Brainard, R. E., Fisher, R., Moews, M., Plaisance, L., and Caley, M. J. (2010). "Coral reef biodiversity," in Life in the World's Oceans, ed. A. D. McIntyre (Hoboken, NJ: Wiley-Blackwell), 65-78.

Koehler, S., Doubský, J., and Kaltenpoth, M. (2013). Dynamics of symbiontmediated antibiotic production reveal efficient long-term protection for beewolf offspring. Front. Zool. 10:3. doi: 10.1186/1742-9994-10-3

Kroiss, J., Kaltenpoth, M., Schneider, B., Schwinger, M.-G., Hertweck, C., Maddula, R. K., et al. (2010). Symbiotic streptomycetes provide antibiotic combination prophylaxis for wasp offspring. Nat. Chem. Biol. 6, 261-263. doi: 10.1038/ nchembio. 331

Kuang, W., Li, J., Zhang, S., and Long, L. (2015). Diversity and distribution of Actinobacteria associated with reef coral Porites lutea. Front. Microbiol. 6:1094. doi: $10.3389 /$ fmicb. 2015.01094

Leal, M. C., Calado, R., Sheridan, C., Alimonti, A., and Osinga, R. (2013). Coral aquaculture to support drug discovery. Trends Biotechnol. 31, 555-561. doi: 10.1016/j.tibtech.2013.06.004

Li, X., Huang, P., Wang, Q., Xiao, L., Liu, M., Bolla, K., et al. (2014). Staurosporine from the endophytic Streptomyces sp. strain CNS-42 acts as a potential biocontrol agent and growth elicitor in cucumber. Antonie Van Leeuwenhoek 106, 515-525. doi: 10.1007/s10482-014-0220-6

Li, Y., Han, L., Rong, H., Li, L., Zhao, L., Wu, L., et al. (2015). Diastaphenazine, a new dimeric phenazine from an endophytic Streptomyces diastaticus subsp. ardesiacus. J. Antibiot. (Tokyo) 68, 210-212. doi: 10.1038/ja.2014.124

Linares, J. F., Gustafsson, I., Baquero, F., and Martinez, J. L. (2006). Antibiotics as intermicrobial signaling agents instead of weapons. Proc. Natl. Acad. Sci. U.S.A. 103, 19484-19489. doi: 10.1073/pnas.0608949103

Ling, L. L., Schneider, T., Peoples, A. J., Spoering, A. L., Engels, I., Conlon, B. P., et al. (2015). A new antibiotic kills pathogens without detectable resistance. Nature 517, 455-459. doi: 10.1038/nature14098

Liu, C., Guan, X., Li, Y., Li, W., Ye, L., Kong, X., et al. (2016). Nocardia camponoti sp. nov., an actinomycete isolated from the head of an ant (Camponotus japonicas Mayr). Int. J. Syst. Evol. Microbiol. 66, 1900-1905. doi: 10.1099/ijsem. 0.000963

Lugo, M. A., Ferrero, M., Menoyo, E., Estévez, M. C., Siñeriz, F., and Anton, A. (2007). Arbuscular mycorrhizal fungi and rhizospheric bacteria diversity along an altitudinal gradient in South American Puna Grassland. Microb. Ecol. 55:705. doi: 10.1007/s00248-007-9313-3

Ma, J. F. (2005). Plant root responses to three abundant soil minerals: silicon, aluminum and iron. Crit. Rev. Plant Sci. 24, 267-281. doi: 10.1080/ 07352680500196017

Mahmoud, H. M., and Kalendar, A. A. (2016). Coral-associated actinobacteria: diversity, abundance, and biotechnological potentials. Front. Microbiol. 7:204. doi: $10.3389 /$ fmicb. 2016.00204

Mattoso, T. C., Moreira, D. D. O., and Samuels, R. I. (2012). Symbiotic bacteria on the cuticle of the leaf-cutting ant Acromyrmex subterraneus subterraneus protect workers from attack by entomopathogenic fungi. Biol. Lett. 8, 461-464. doi: $10.1098 / \mathrm{rsbl} .2011 .0963$

Mehbub, M. F., Tanner, J. E., Barnett, S. J., Franco, C. M. M., and Zhang, W. (2016). The role of sponge-bacteria interactions: the sponge Aplysilla rosea challenged by its associated bacterium Streptomyces ACT-52A in a controlled aquarium system. Appl. Microbiol. Biotechnol. 100, 10609-10626. doi: 10.1007/s00253016-7878-9

Merzaeva, O. V., and Shirokikh, I. G. (2010). The production of auxins by the endophytic bacteria of winter rye. Appl. Biochem. Microbiol. 46, 44-50. doi: 10.1134/S0003683810010072

Meschke, H., Walter, S., and Schrempf, H. (2012). Characterization and localization of prodiginines from Streptomyces lividans suppressing Verticillium dahliae in the absence or presence of Arabidopsis thaliana. Environ. Microbiol. 14, 940-952. doi: 10.1111/j.1462-2920.2011.02665.x

Milshteyn, A., Schneider, J. S., and Brady, S. F. (2014). Mining the metabiome: identifying novel natural products from microbial communities. Chem. Biol. 21, 1211-1223. doi: 10.1016/j.chembiol.2014.08.006
Nabti, E., Bensidhoum, L., Tabli, N., Dahel, D., Weiss, A., Rothballer, M., et al. (2014). Growth stimulation of barley and biocontrol effect on plant pathogenic fungi by a Cellulosimicrobium sp. strain isolated from salt-affected rhizosphere soil in northwestern Algeria. Eur. J. Soil Biol. 61, 20-26. doi: 10.1016/j.ejsobi. 2013.12.008

Onaka, H., Mori, Y., Igarashi, Y., and Furumai, T. (2011). Mycolic acid-containing bacteria induce natural-product biosynthesis in Streptomyces species. Appl. Environ. Microbiol. 77, 400-406. doi: 10.1128/AEM.01337-10

Pham, T. M., Wiese, J., Wenzel-Storjohann, A., and Imhoff, J. F. (2015). Diversity and antimicrobial potential of bacterial isolates associated with the soft coral Alcyonium digitatum from the Baltic Sea. Antonie Van Leeuwenhoek 109, 105-119. doi: 10.1007/s10482-015-0613-1

Pimentel-Elardo, S. M., Sørensen, D., Ho, L., Ziko, M., Bueler, S. A., Lu, S., et al. (2015). Activity-independent discovery of secondary metabolites using chemical elicitation and cheminformatic inference. ACS Chem. Biol. 10, 2616-2623. doi: 10.1021/acschembio.5b00612

Poulsen, M., Erhardt, D. P., Molinaro, D. J., Lin, T.-L., and Currie, C. R. (2007). Antagonistic bacterial interactions help shape host-symbiont dynamics within the fungus-growing ant-microbe mutualism. PLoS ONE 2:e960. doi: 10.1371/ journal.pone.0000960

Reynolds, H. T., and Currie, C. R. (2004). Pathogenicity of Escovopsis weberi: the parasite of the attine ant-microbe symbiosis directly consumes the antcultivated fungus. Mycologia 96, 955-959. doi: 10.2307/3762079

Romero, F., Espliego, F., Pérez Baz, J., García de Quesada, T., Grávalos, D., de la Calle, F., et al. (1997). Thiocoraline, a new depsipeptide with antitumor activity produced by a marine Micromonospora. I. Taxonomy, fermentation, isolation, and biological activities. J. Antibiot. (Tokyo) 50, 734-737. doi: 10.7164/ antibiotics.50.734

Rungin, S., Indananda, C., Suttiviriya, P., Kruasuwan, W., Jaemsaeng, R., and Thamchaipenet, A. (2012). Plant growth enhancing effects by a siderophoreproducing endophytic streptomycete isolated from a Thai jasmine rice plant (Oryza sativa L. cv. KDML105). Antonie Van Leeuwenhoek 102, 463-472. doi: 10.1007/s10482-012-9778-z

Ryan, R. P., and Dow, J. M. (2008). Diffusible signals and interspecies communication in bacteria. Microbiol. Read. Engl. 154, 1845-1858. doi: 10. 1099/mic.0.2008/017871-0

Schatz, A., Bugle, E., and Waksman, S. A. (1944). Streptomycin, a substance exhibiting antibiotic activity against gram-positive and gramnegative bacteria. Exp. Biol. Med. 55, 66-69. doi: 10.3181/00379727-5514461

Schneemann, I., Nagel, K., Kajahn, I., Labes, A., Wiese, J., and Imhoff, J. F. (2010). Comprehensive investigation of marine actinobacteria associated with the sponge Halichondria panicea. Appl. Environ. Microbiol. 76, 3702-3714. doi: 10.1128/AEM.00780-10

Schoenian, I., Spiteller, M., Ghaste, M., Wirth, R., Herz, H., and Spiteller, D. (2011). Chemical basis of the synergism and antagonism in microbial communities in the nests of leaf-cutting ants. Proc. Natl. Acad. Sci. U.S.A. 108, 1955-1960. doi: $10.1073 /$ pnas. 1008441108

Schultz, T. R., and Brady, S. G. (2008). Major evolutionary transitions in ant agriculture. Proc. Natl. Acad. Sci. U.S.A. 105, 5435-5440. doi: 10.1073/pnas. 0711024105

Seipke, R. F., Barke, J., Brearley, C., Hill, L., Yu, D. W., Goss, R. J. M., et al. (2011). A single Streptomyces symbiont makes multiple antifungals to support the fungus farming ant Acromyrmex octospinosus. PLoS ONE 6:e22028. doi: 10.1371/journal.pone.0022028

Seipke, R. F., Kaltenpoth, M., and Hutchings, M. I. (2012). Streptomyces as symbionts: an emerging and widespread theme? FEMS Microbiol. Rev. 36, 862-876. doi: 10.1111/j.1574-6976.2011.00313.x

Sit, C. S., Ruzzini, A. C., Arnam, E. B. V., Ramadhar, T. R., Currie, C. R., and Clardy, J. (2015). Variable genetic architectures produce virtually identical molecules in bacterial symbionts of fungus-growing ants. Proc. Natl. Acad. Sci. U.S.A. 112, 13150-13154. doi: 10.1073/pnas.1515348112

Solans, M., Scervino, J. M., Messuti, M. I., Vobis, G., and Wall, L. G. (2016). Potential biocontrol actinobacteria: rhizospheric isolates from the Argentine Pampas lowlands legumes. J. Basic Microbiol. 56, 1289-1298. doi: 10.1002/jobm. 201600323

Solans, M., Vobis, G., Cassán, F., Luna, V., and Wall, L. G. (2011). Production of phytohormones by root-associated saprophytic actinomycetes isolated from 
the actinorhizal plant Ochetophila trinervis. World J. Microbiol. Biotechnol. 27, 2195-2202. doi: 10.1007/s11274-011-0685-7

Stierle, A. C., Cardellina, J. H., and Singleton, F. L. (1988). A marine Micrococcus produces metabolites ascribed to the sponge Tedania ignis. Experientia 44:1021. doi: 10.1007/BF01939910

Strohm, E., and Linsenmair, K. E. (2001). Females of the European beewolf preserve their honeybee prey against competing fungi. Ecol. Entomol. 26, 198-203. doi: 10.1046/j.1365-2311.2001.00300.x

Subramani, R., and Aalbersberg, W. (2012). Marine actinomycetes: an ongoing source of novel bioactive metabolites. Microbiol. Res. 167, 571-580. doi: 10 . 1016/j.micres.2012.06.005

Subramani, R., and Aalbersberg, W. (2013). Culturable rare Actinomycetes: diversity, isolation and marine natural product discovery. Appl. Microbiol. Biotechnol. 97, 9291-9321. doi: 10.1007/s00253-013-5229-7

Subramaniam, G., Arumugam, S., and Rajendran, V. (2016). Plant Growth Promoting Actinobacteria: A New Avenue for Enhancing the Productivity and Soil Fertility of Grain Legumes. Singapore: Springer.

Toumatia, O., Compant, S., Yekkour, A., Goudjal, Y., Sabaou, N., Mathieu, F., et al. (2016). Biocontrol and plant growth promoting properties of Streptomyces mutabilis strain IA1 isolated from a Saharan soil on wheat seedlings and visualization of its niches of colonization. South Afr. J. Bot. 105, 234-239. doi: 10.1016/j.sajb.2016.03.020

Traxler, M. F., and Kolter, R. (2015). Natural products in soil microbe interactions and evolution. Nat. Prod. Rep. 32, 956-970. doi: 10.1039/c5np0 $0013 \mathrm{k}$

Traxler, M. F., Watrous, J. D., Alexandrov, T., Dorrestein, P. C., and Kolter, R. (2013). Interspecies interactions stimulate diversification of the Streptomyces coelicolor secreted metabolome. mBio 4:e459-13. doi: 10.1128/mBio.00459-13

Udwary, D. W., Zeigler, L., Asolkar, R. N., Singan, V., Lapidus, A., Fenical, W., et al. (2007). Genome sequencing reveals complex secondary metabolome in the marine actinomycete Salinispora tropica. Proc. Natl. Acad. Sci. U.S.A. 104, 10376-10381. doi: 10.1073/pnas.0700962104

Ueda, K., Kawai, S., Ogawa, H., Kiyama, A., Kubota, T., Kawanobe, H., et al. (2000). Wide distribution of interspecific stimulatory events on antibiotic production and sporulation among Streptomyces species. J. Antibiot. (Tokyo) 53, 979-982. doi: 10.7164/antibiotics.53.979

Van Arnam, E. B., Ruzzini, A. C., Sit, C. S., Currie, C. R., and Clardy, J. (2015). A rebeccamycin analog provides plasmid-encoded niche defense. J. Am. Chem. Soc. 137, 14272-14274. doi: 10.1021/jacs.5b09794

Van Middlesworth, F., and Cannell, R. P. (1998). "Dereplication and partial identification of natural products," in Natural Products Isolation Methods in Biotechnology, ed. R. P. Cannell (Totowa, NJ: Humana Press), 279-327. doi: 10.1007/978-1-59259-256-2_10

Vetsigian, K., Jajoo, R., and Kishony, R. (2011). Structure and evolution of Streptomyces interaction networks in soil and in silico. PLoS Biol. 9:e1001184. doi: 10.1371 /journal.pbio. 1001184
Xi, L., Ruan, J., and Huang, Y. (2012). Diversity and biosynthetic potential of culturable actinomycetes associated with marine sponges in the China Seas. Int. J. Mol. Sci. 13, 5917-5932. doi: 10.3390/ijms13055917

Xu, Y., and Her, C. (2015). Inhibition of topoisomerase (DNA) I (TOP1): DNA damage repair and anticancer therapy. Biomolecules 5, 1652-1670. doi: 10.3390/ biom 5031652

Xue, L., Xue, Q., Chen, Q., Lin, C., Shen, G., and Zhao, J. (2013). Isolation and evaluation of rhizosphere actinomycetes with potential application for biocontrol of Verticillium wilt of cotton. Crop Prot. 43, 231-240. doi: 10.1016/j. cropro.2012.10.002

Yamanaka, K., Oikawa, H., Ogawa, H., Hosono, K., Shinmachi, F., Takano, H., et al. (2005). Desferrioxamine e produced by Streptomyces griseus stimulates growth and development of Streptomyces tanashiensis. Microbiol. Read. Engl. 151, 2899-2905. doi: 10.1099/mic.0.28139-0

Yamanaka, K., Reynolds, K. A., Kersten, R. D., Ryan, K. S., Gonzalez, D. J., Nizet, V., et al. (2014). Direct cloning and refactoring of a silent lipopeptide biosynthetic gene cluster yields the antibiotic taromycin A. Proc. Natl. Acad. Sci. U.S.A. 111, 1957-1962. doi: 10.1073/pnas.1319584111

Yan, L.-L., Han, N.-N., Zhang, Y.-Q., Yu, L.-Y., Chen, J., Wei, Y.-Z., et al. (2010). Antimycin A18 produced by an endophytic Streptomyces albidoflavus isolated from a mangrove plant. J. Antibiot. (Tokyo) 63, 259-261. doi: 10.1038/ja.2010.21

Yarnold, J. E., Hamilton, B. R., Welsh, D. T., Pool, G. F., Venter, D. J., and Carroll, A. R. (2012). High resolution spatial mapping of brominated pyrrole-2aminoimidazole alkaloids distributions in the marine sponge Stylissa flabellata via MALDI-mass spectrometry imaging. Mol. Biosyst. 8, 2249-2259. doi: 10. $1039 / \mathrm{c} 2 \mathrm{mb} 25152 \mathrm{c}$

Zhang, J., Wang, J.-D., Liu, C.-X., Yuan, J.-H., Wang, X.-J., and Xiang, W.-S. (2014). A new prenylated indole derivative from endophytic actinobacteria Streptomyces sp. neau-D50. Nat. Prod. Res. 28, 431-437. doi: 10.1080/14786419. 2013.871546

Ziemert, N., Lechner, A., Wietz, M., Millán-Aguiñaga, N., Chavarria, K. L., and Jensen, P. R. (2014). Diversity and evolution of secondary metabolism in the marine actinomycete genus Salinispora. Proc. Natl. Acad. Sci. U.S.A. 111, E1130-E1139. doi: 10.1073/pnas.1324161111

Conflict of Interest Statement: The authors declare that the research was conducted in the absence of any commercial or financial relationships that could be construed as a potential conflict of interest.

Copyright (c) 2017 Behie, Bonet, Zacharia, McClung and Traxler. This is an openaccess article distributed under the terms of the Creative Commons Attribution License (CC BY). The use, distribution or reproduction in other forums is permitted, provided the original author(s) or licensor are credited and that the original publication in this journal is cited, in accordance with accepted academic practice. No use, distribution or reproduction is permitted which does not comply with these terms. 